\title{
Ultrasound Markers of Implantation
}

\author{
Luis T Mercé, María J Barco, Asim Kurjak
}

\begin{abstract}
Endometrial 3D power Doppler indices change significantly during the normal menstrual cycle. Vascularity indices of the endometrial and subendometrial vessels increase throughout the proliferative phase of the menstrual cycle, reaching a maximum value 2 to 3 days prior to ovulation. From this peak, vascularity indices decrease and reach a nadir 2 to 5 days after ovulation. Reduced endometrial perfusion assessed by 3D power Doppler ultrasound is most likely related to increased uterine contractility. If prolonged, it may cause endometrial hypoxia, leading to detrimental effect on implantation potential. In normal spontaneous menstrual cycles, endometrial vascular indices increase progressively during the course of the luteal phase. Endometrial and subendometrial perfusion is negatively affected by serum estradiol concentrations, which can explain why patients with hyperstimulation have lower endometrial and subendometrial blood flow during the early luteal phase. Our results indicate that $3 \mathrm{D}$ power Doppler implantation markers are crucial for planning a single embryo transfer in order to select the most suitable cycle for transfer of a single cryopreserved embryo.
\end{abstract}

Keywords: Endometrial perfusion, 3D power Doppler vascularity indices, Implantation potential, Markers of implantation, IVF/ embryo transfer.

How to cite this article: Mercé LT, Barco MJ, Kurjak A. Ultrasound Markers of Implantation. Donald School J Ultrasound Obstet Gynecol 2012;6(1):14-26.

\section{Source of support: Nil}

Conflict of interest: None declared

\section{INTRODUCTION}

Implantation is the penetration of the embryo in the uterine endometrium. This process is characterized by taking place only during a very specific period called 'implantation window'. Between days 19 to 22 of the menstrual cycle, synchronization between the embryo development blastocyst stage and endometrium receptivity occurs.

Current assisted reproduction techniques (ART), especially in vitro fertilization (IVF), makes possible to know the implantation process and the best conditions to achieve a successful outcome. Today we know that obtaining a pregnancy after embryo transfer is closely related to the embryo quality, endometrium receptivity and the transfer technique.

Currently, it is firmly believed that to increase pregnancy rates and decrease multiple gestations through ART, a better knowledge of implantation markers is required. Ultrasonography, color Doppler, the recently introduced 3D ultrasonography and power Doppler angiography offer the possibility to assess the uterine and ovarian markers of implantation to be able to use them in our clinical practice. As it is described below, endometrial ultrasound and Doppler parameters give us the information related to endometrial receptivity and can be used as implantation markers.

\section{ULTRASOUND IMPLANTATION MARKERS}

Real-time ultrasonography allows us the study of two main implantation markers: Endometrial thickness and endometrial morphological patterns. ${ }^{1}$ Pulsed and color Doppler assessment is applied to the study of different variables of uterine and endometrial perfusion that are also used as receptivity factors. ${ }^{2}$ Three-dimensional ultrasound and power Doppler angiography (3D US-PDA) have the advantage of simultaneous assessment of endometrial volume and endometrial blood flow. ${ }^{3}$

\section{Endometrial Thickness and Volume}

Endometrial thickness is defined as the maximal distance between the echogenic interfaces of the myometrium and the endometrium when measured on the longitudinal plane of the uterus (Fig. 1A). Significant differences of this thickness have not been observed between spontaneous and stimulated cycles even using different stimulation protocols. ${ }^{4}$ This finding suggests that there is a maximal endometrial response induced by estrogens that is achieved during the natural ovulatory cycle. ${ }^{5}$ A significant correlation between the endometrial thickness and endometrial histopathological dating has not been found either. ${ }^{6}$

In IVF stimulated cycles, the endometrium increases $1.9 \mathrm{~mm}$ between days 7 and 9 of the stimulation treatment, $0.9 \mathrm{~mm}$ between days 9 and 11 and $0.6 \mathrm{~mm}$ between the latter and the day of human chorionic gonadotropin (hCG) administration. ${ }^{7}$ The endometrial thickness increases $0.5 \mathrm{~mm}$ per day ${ }^{8}$ or does not change until the embryo transfer day. ${ }^{7}$ Significant differences have not been observed in endometrial thickness between hCG day and the day of embryo transfer, ${ }^{9}$ which clearly has practical implications to choose the timing for the measurement.

There is not enough data to demonstrate, if a linear relationship exists between endometrial thickness and the probability of pregnancy after an ART..$^{10}$ Endometrial thickness in a great number of cycles studied shows similar ranges in conception cycles ( $\mathrm{n}=514$; 8.6-11.8 $\mathrm{mm}$ ) as well as the ones that did not conceive $(n=1110 ; 8.6-11.9 \mathrm{~mm}) .{ }^{10}$ 
However, in the conception cycles there is an accelerated increase in the endometrial thickness during the luteal phase that reaches significant differences regarding to that in nonconception cycles 14 days after the day of oocyte retrieval. ${ }^{8,11}$

As an implantation marker, endometrial thickness is characterized by its significant sensitivity (95-100\%), but also shows a high number of false positives (78-97\%); ${ }^{10}$ therefore, the main advantage is a high negative predictive value (87-100\%) (Table 1). An endometrial thickness lower than $7 \mathrm{~mm}$ on the day of hCG administration is considered an acceptable marker for nonreceptive endometrium. It has also been reported that implantation and pregnancy rates are negatively affected by the endometrium being thicker than $14 \mathrm{~mm},{ }^{12}$ although data from recent studies do not support this finding. ${ }^{13,14}$ On the other hand, a very thin $(<6 \mathrm{~mm})$ or very thick $(>13 \mathrm{~mm})$ endometrium has also been associated with an increase in early miscarriages. ${ }^{15}$

In a donor oocyte program with hormone replacement therapy (HRT) it is proven that pregnancy rates and endometrial thickness decrease at the same time. ${ }^{16}$ When endometrial thickness is equal or greater than $9 \mathrm{~mm}$ a pregnancy rate of $68 \%$ is achieved, diminishing to $20 \%$ when endometrial thickness is less than $6 \mathrm{~mm} .{ }^{16}$ Although it is possible to achieve pregnancies with a thin endometrium, ${ }^{17}$ this is always a bad predictive factor that requires further study of the endometrium. ${ }^{16}$ In a retrospective study of 1,228 IVF/ICSI (Intracytoplasmic sperm injection) cycles, endometrial thickness on the day of embryo transfer was positively associated with pregnancy rates. Improved pregnancy rates were found when the endometrium reached at least $10 \mathrm{~mm}$ and rates further improved with additional increases in endometrial thickness between 10 and $14 \mathrm{~mm}$. Nevertheless, these authors did not find any significant difference in endometrial thickness between ongoing pregnancies and the ones resulting in a first-trimester loss. ${ }^{18}$ After a retrospective analysis of 897 IVF-ET cycles, an increased endometrial thickness on the
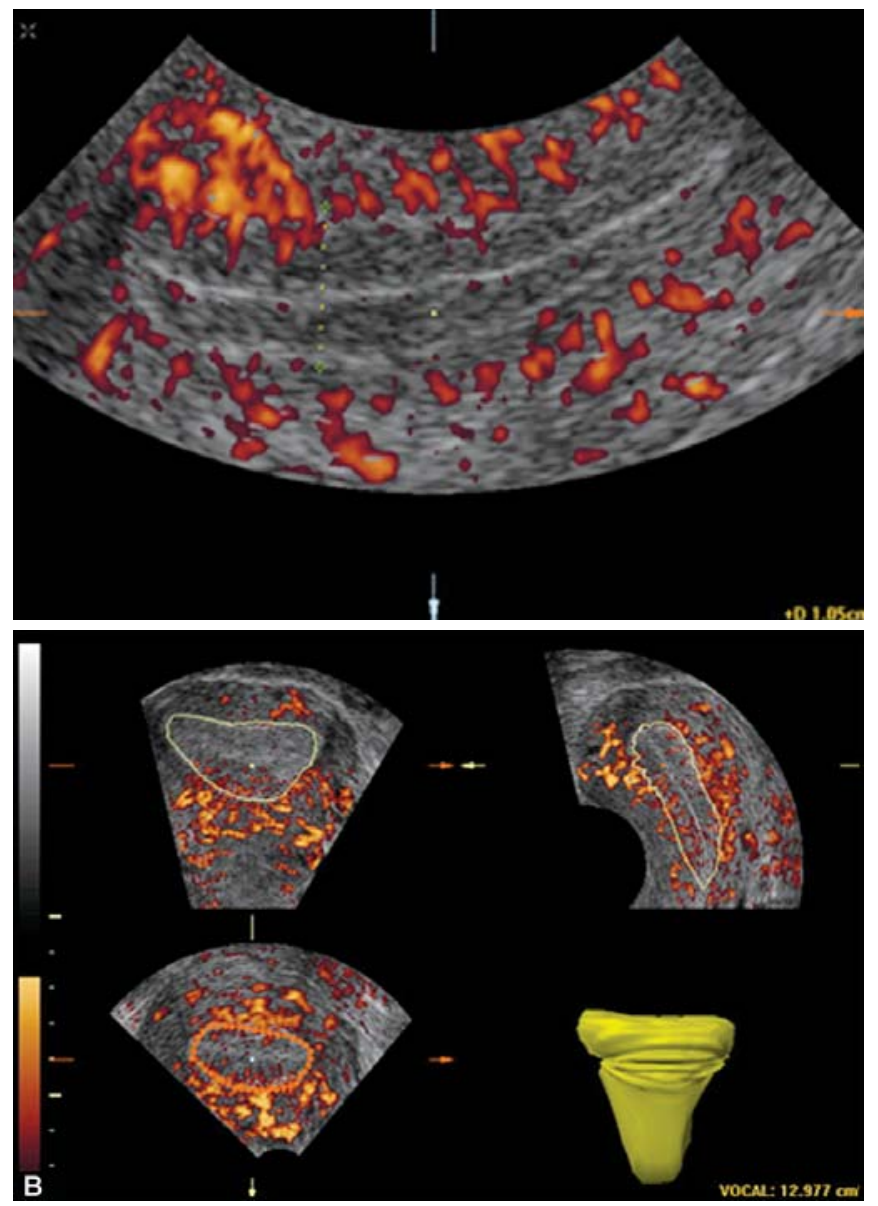

Figs $1 \mathrm{~A}$ and $\mathbf{B}$ : (A) Endometrial thickness measured on the longitudinal plane of the uterus; (B) Endometrial volume assessed by three-dimensional ultrasound

hCG day administration is associated with an improved outcome, but this relationship also depends on patient age, length of ovarian stimulation and embryo quality. A thin endometrium is associated with reduced pregnancy rates only for the transfers of less good quality embryos. ${ }^{14}$ More recently, it was evaluated that the relationship between endometrial thickness and embryo implantation by a retrospective study on 1,294 IVF cycles with transfer of two blastocyst-stage embryos. ${ }^{19}$ The authors demonstrated a significant relationship between both variables. Pregnancy

\begin{tabular}{llccc}
\multicolumn{5}{c}{ Table 1: Predictive values of sonographic and Doppler parameters to achieve pregnancy with } \\
assisted reproduction techniques
\end{tabular}

\footnotetext{
${ }^{1}$ All the values are percentages; ${ }^{2}$ According to different authors, techniques and limits of endometrial thickness, between 6 and $10 \mathrm{~mm} ;{ }^{3}$ According to different authors and techniques; ${ }^{4}$ For a pulsatility index of uterine arteries between 3 and 3.3 according to different authors and techniques. Se: Sensitivity; Sp: Specificity; PPV: Positive predictive value; NPV: Negative predictive value.
} 
Table 2: Intraobserver repeatability of measurements of endometrial volume (EV), vascularization index (VI), flow index (FI), vascularization flow Index (VFI) according to acquisition plane ( $A$ and $C$ ) and rotation step $\left(9^{\circ}\right.$ and $15^{\circ}$ angle) for endometrium

\begin{tabular}{|c|c|c|c|c|c|c|c|}
\hline Parameter & Plane & Rotation step & Datasets (n) & $\begin{array}{l}\text { Mean } \\
\text { difference* }\end{array}$ & $S D$ & $I C C$ & $\begin{array}{l}95 \%-\mathrm{Cl} \\
\text { ICC }\end{array}$ \\
\hline \multirow[t]{4}{*}{ EV } & $A$ & $15^{\circ}$ & 80 & -0.04 & 0.85 & 0.99 & $0.98-1.00$ \\
\hline & & $9^{\circ}$ & 80 & 0.29 & 1.72 & 0.97 & 0.95-0.99 \\
\hline & $\mathrm{C}$ & $15^{\circ}$ & 80 & 0.25 & 1.44 & 0.98 & $0.96-0.99$ \\
\hline & & $9^{\circ}$ & 80 & -0.22 & 1.20 & 0.98 & $0.97-0.99$ \\
\hline \multirow[t]{4}{*}{ VI } & $A$ & $15^{\circ}$ & 80 & -0.77 & 4.34 & 0.95 & $0.91-0.97$ \\
\hline & & $9^{\circ}$ & 80 & -0.97 & 3.54 & 0.96 & $0.93-0.98$ \\
\hline & $\mathrm{C}$ & $15^{\circ}$ & 80 & -1.07 & 4.27 & 0.95 & $0.91-0.97$ \\
\hline & & $9^{\circ}$ & 80 & -1.07 & 3.62 & 0.97 & $0.94-0.98$ \\
\hline \multirow[t]{4}{*}{$\mathrm{FI}$} & $A$ & $15^{\circ}$ & 80 & -0.38 & 1.84 & 0.91 & $0.83-0.95$ \\
\hline & & $9^{\circ}$ & 80 & -0.07 & 1.85 & 0.91 & $0.83-0.95$ \\
\hline & $\mathrm{C}$ & $15^{\circ}$ & 80 & -0.07 & 1.70 & 0.91 & $0.84-0.95$ \\
\hline & & $9^{\circ}$ & 80 & -0.27 & 1.82 & 0.90 & $0.82-0.95$ \\
\hline \multirow[t]{4}{*}{ VFI } & $A$ & $15^{\circ}$ & 80 & -0.21 & 1.38 & 0.95 & $0.91-0.98$ \\
\hline & & $9^{\circ}$ & 80 & -0.31 & 1.17 & 0.96 & $0.93-0.98$ \\
\hline & $\mathrm{C}$ & $15^{\circ}$ & 80 & -0.30 & 1.42 & 0.95 & $0.92-0.98$ \\
\hline & & $9^{\circ}$ & 80 & -0.27 & 1.23 & 0.97 & $0.94-0.98$ \\
\hline
\end{tabular}

* Mean of difference between both measurements. ICC: intraclass correlation coefficient; $95 \%$-Cl: 95\% confidence interval for ICC; SD: standard deviation

rates increased gradually with increasing endometrial thickness. This relationship is independent of the patient age, the number and quality of embryos transferred. Nevertheless, good pregnancy rates can be achieved with endometrial lines of only 6 to $7 \mathrm{~mm}$, when good-quality blastocysts are transferred. ${ }^{19}$

Three-dimensional technology has added to our daily practice in reproduction the use of endometrial volume as an implantation marker (Fig. 1B). ${ }^{3}$ Our team has recently demonstrated an excellent intra- and inter-observer reproducibility of this measurement. ${ }^{20,21}$ The best intraclass correlation indices to obtain the endometrial volume and endometrial vascularity indices with the virtual organ computer-aided analysis (VOCAL) program are achieved working in the coronal or "C" plane with a rotational angle of $9^{\circ}$ (Table 2). ${ }^{21}$

During spontaneous menstrual cycles, the changes in uterine/endometrial volume ratio proved a good correlation with the day of menstrual cycle. ${ }^{22}$ Endometrial volume increased significantly during the follicular phase, reaching a plateau around the time of ovulation and remaining relatively stable throughout the luteal phase. ${ }^{23,24}$ Parous women showed endometrial volumes significantly larger than nulliparous women. ${ }^{23}$ According to our results, basal endometrial volumes after pituitary suppression with a long gonadotropin-releasing hormone $(\mathrm{GnRH})$ protocol are significantly smaller than preovulatory endometrial volumes after ovarian simulation with single or multiple preovulatory follicles and midluteal endometrial volumes (Fig. 2A).

A pioneering study ${ }^{25}$ demonstrated that endometrial volume at the time of ET is related to pregnancy achievement. An endometrial volume larger than $2 \mathrm{ml}$ could be a prerequisite for good endometrial receptivity given that pregnancy and implantation rates were significantly lower with a smaller endometrial volume. ${ }^{25}$ More recently, an endometrial volume of $2.5 \mathrm{ml}$ on the day of ET has been proposed as a reliable threshold value to predict pregnancy after ET in IVF/ICSI cycles. ${ }^{26}$ The analysis of the endometrium on the hCG day by 3D ultrasonography in 80 infertile women undergoing a first IVF-ICSI cycle, proved that endometrial volume is significantly greater in women that got pregnant, whereas endometrial thickness is unchanged (Table 3). Other studies have not demonstrated that endometrial volume is predictive for pregnancy. ${ }^{27-31}$ This could be explained by methodological differences in volume calculation. Whereas we perform VOCAL program in plane $\mathrm{C}$ with a $9^{\circ}$ rotational steps, some authors use a nonrotational method ${ }^{27-29}$ or apply the VOCAL program but delineating and measuring an inferior number of planes. ${ }^{30,31}$ In addition, endometrial volumes evaluated in different cycle day, such as the day of hCG administration, the day of oocyte retrieval or the day of embryo transfer, might be difficult to compare. Comparing endometrial volume before hCG administration with that on the day of oocyte retrieval, it significantly decreased after hCG 
Table 3: Endometrial thickness, volume, vascularization index, flow index and vascularization flow index on the hCG day in an IVF/ICSI program according to outcome

\begin{tabular}{llll}
\hline & Pregnant $(n=38)$ & Nonpregnant $(n=39)$ & $p$ \\
\hline Endometrial thickness $(\mathrm{mm})$ & $12.29 \pm 2.71$ & $12.15 \pm 2.31$ & 0.81 \\
${\text { Endometrial volume }(\mathrm{ml})^{\mathrm{a}}}_{\text {Vascularization index }}^{5.63(2.67-16.64)}$ & $4.82(2.05-9.24)$ & 0.02 \\
Flow index & $21.19 \pm 8.91$ & $16.05 \pm 9.84$ & 0.02 \\
Vascularization flow index & $28.12 \pm 3.90$ & $24.27 \pm 3.71$ & $<0.001$ \\
\hline
\end{tabular}

Data are presented as mean \pm standard deviation or $\mathrm{n}(\%)$ or ${ }^{\mathrm{a}}$ median (range)
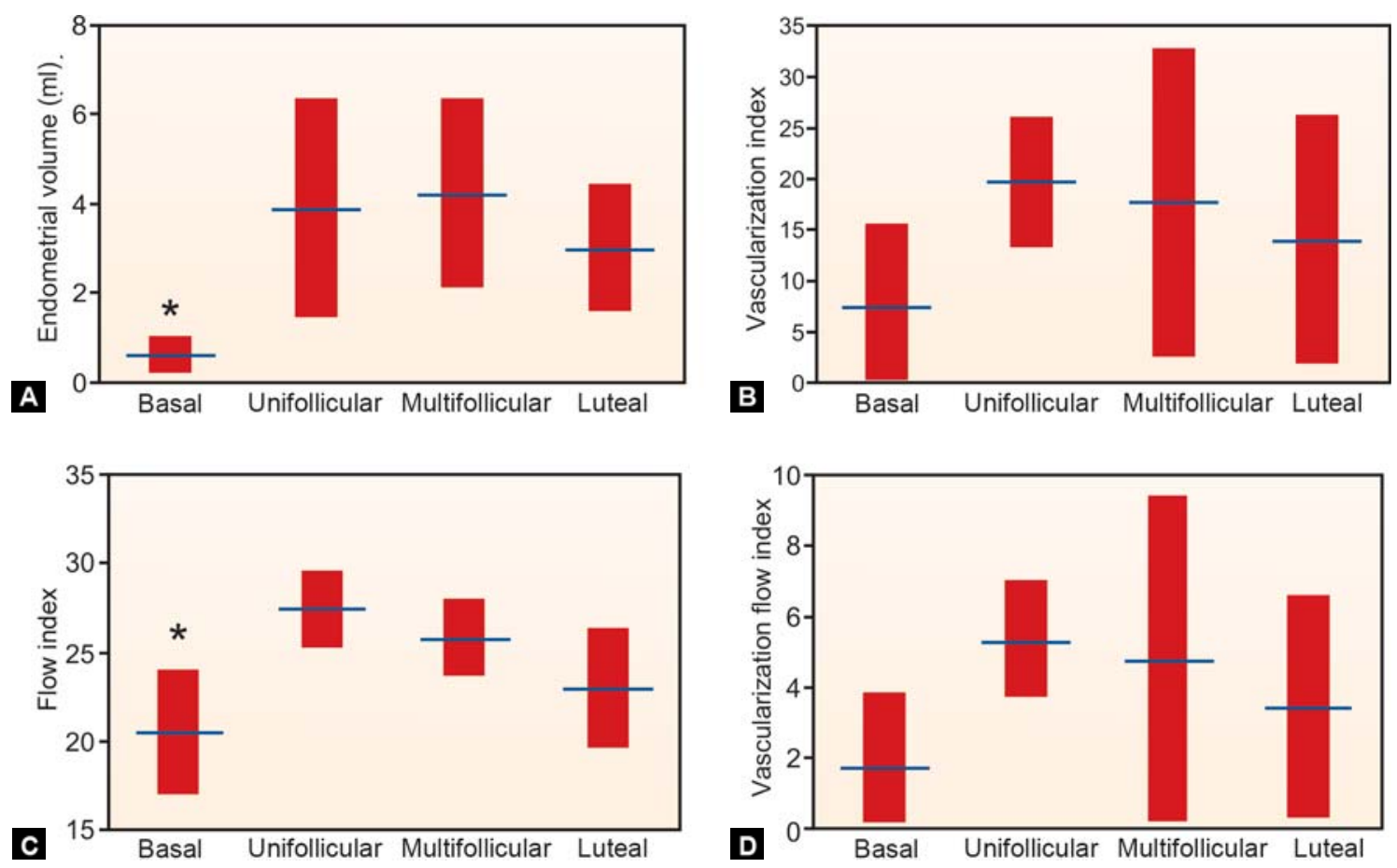

Figs 2A to D: (A) Endometrial volume; (B) Vascularization index; (C) Flow index; (D) Vascularization flow index according to ovarian functional status. Basal (12 cases): on the day of pituitary suppression confirmation after a standard long GnRH protocol; Unifollicular (11 cases): on the day of hCG administration after low doses of FSH ovarian stimulation getting a single follicle development; Multifollicular (14 cases): on the day of hCG administration after standard doses for ovarian stimulation and multifollicular development; Luteal (10 cases): on mesoluteal phase in normal ovulatory cycles. ${ }^{*} p<0.05$

injection in women who conceived but not in those who did not conceive. ${ }^{30}$ Our group has recently published a prospective clinical study in eighty women who underwent IVF cycle. ${ }^{32}$ Endometrial volume was significantly increased in the pregnant group (38 cycles) comparatively with nonpregnant group (39 cycles). On the contrary, endometrial thickness and triple-line pattern did not show significant differences between both groups. According to our results, endometrial volume measured with 3D ultrasound is a useful parameter in predicting outcome cycle in IVF and ET procedure. ${ }^{32}$

Other parameters have been assessed, such as the length and the width of the endometrium ${ }^{7}$ or the endometrial area, ${ }^{33}$ although no advantage overendometrial thickness or volume in using these parameters has been demonstrated.

\section{Endometrial Pattern}

The endometrial pattern is the relative echogenicity that the endometrium presents with respect to the adjacent myometrium. Its importance as an implantation marker lies in that it reflects the degree of histological development. ${ }^{34}$

During the proliferative phase of the menstrual cycle, the endometrium achieves a 'triple line' morphology (Fig. 3A) where the echogenic central line represents the uterine cavity and the outer echogenic lines reflect the basal layer of the endometrium or the interface between the endometrium and, the myometrium. The hypoechogenic zones between the outer and central line are the functional layers of the endometrium. This image is attributed to the glandular disposition, reduced secretion and scarce stromal edema. ${ }^{35}$ 
During the secretory phase of the menstrual cycle, the endometrium acquires a hyperechogenic morphology (Fig. 3B) that is due to stromal edema, spiralization and secretion of the endometrial glands caused by the action of progesterone. ${ }^{2,7,11,36}$ However, since a correlation between echogenicity and progesterone has not been demonstrated, ${ }^{9,37}$ other factors, such as androgen and gonadotropin effects, could explain these changes. ${ }^{38,39}$

The subendometrial halo or uterine junctional zone between the endometrium and the myometrium is a distinct compartment of the myometrium comprising tightly packed muscle cells and an increased vascularity. ${ }^{40}$

Although initially four different myometrial echogenicity patterns were described ${ }^{41}$ it were lately reduced to three, ${ }^{42}$ because a 'triple line' pattern as the only positive implantation marker results more predictive ${ }^{43}$ (Fig. 3C). The endometrial pattern does not appear to be influenced by the ovarian stimulation protocol and it is also present when hormonal replacement for frozen ET is carried out. ${ }^{5}$ Significant differences of the endometrial morphological pattern between hCG day and the transfer day have not been observed either. ${ }^{9}$

A 'triple line' endometrium is the ultrasound marker that most accurately reflects endometrial receptivity, while the 'nontriple-line' pattern is frequently associated with nonconception cycles, although the possibility of implantation must never be excluded. ${ }^{10}$ Just as with thickness, the 'triple line' endometrial pattern has high sensitivity (79-100\%) but an elevated percentage of false positives (57-91\%) also, subsequently it has an additional interest by its high negative predictive value (75-100\%) (Table 1). Although achieving a pregnancy with a 'nontriple-line' pattern is possible, its frequency is low. ${ }^{5}$

Since, the increase in echogenicity during the follicular phase is the best endometrial parameter to indicate low receptivity, an attempt has been made to evaluate this characteristic by computerized analysis of endometrial morphology. ${ }^{2,11,36,44}$ During the menstrual cycle, myometrial echogenicity increases significantly in both spontaneous and stimulated cycles, ${ }^{11,44}$ but the most important fact is that implantation and pregnancy rates decrease progressively as myometrial echogenicity increases on the day of hCG administration. ${ }^{11,36}$ Therefore, there is an inverse relationship between the extent of endometrial echogenicity transformation and the possibility of pregnancy. More recently it has been also demonstrated a positive relationship between trilaminar pattern with successful implantation and ongoing pregnancy in IVF/ICSI cycles using antagonists. ${ }^{45}$ Nevertheless, some authors think that combined analysis of endometrial thickness and pattern on the day of hCG administration is a better predictor of the outcome of IVF/
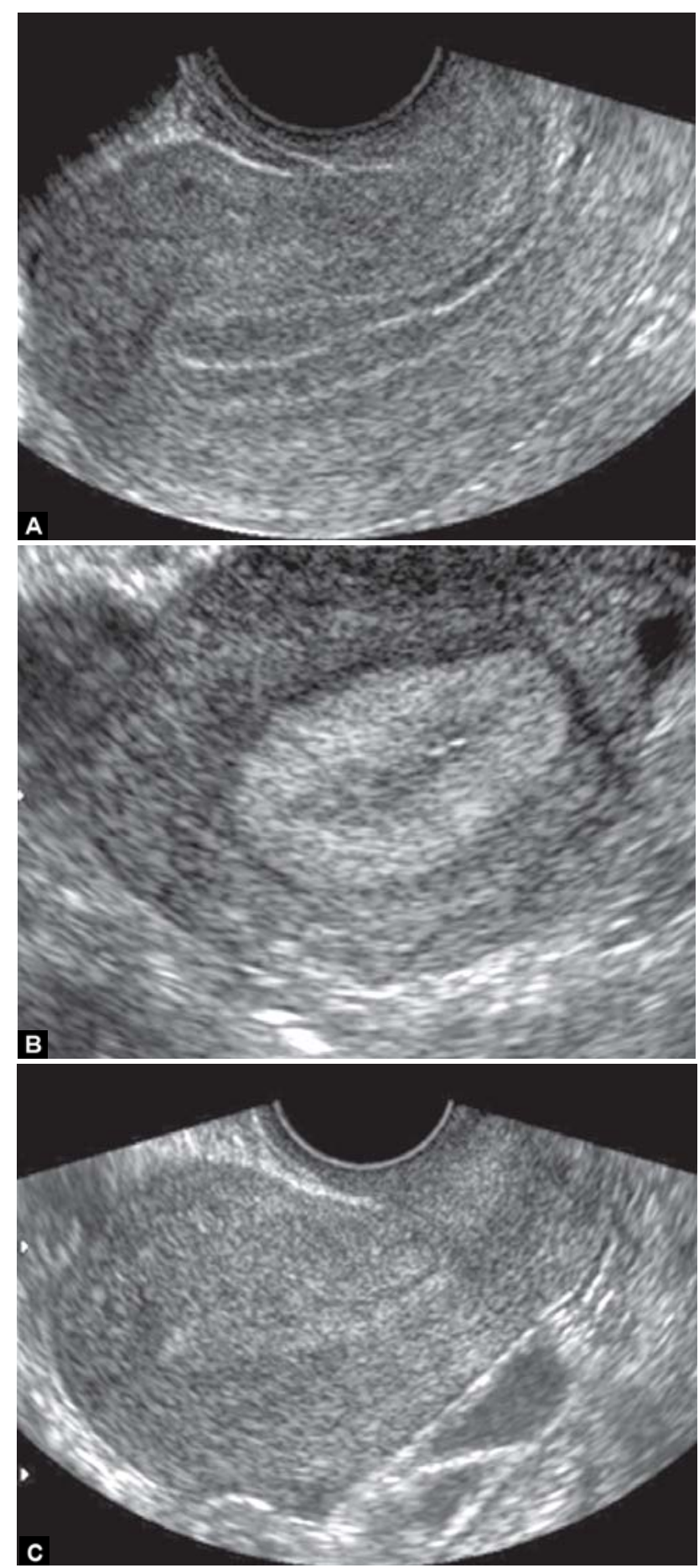

Figs 3A to C: Endometrial echogenicity patterns: (A) Multilayered proliferative endometrium or 'triple line' pattern; (B) Nonmultilayered endometrium; (C) Secretory endometrium

ICSI-ET and may be more helpful for patient counseling than the separate analyses. ${ }^{46}$

The normal luteal endometrial pattern has been also implied as an implantation marker. A nonhomogeneous hyperechogenic pattern three days after ET has been associated with lower pregnancy rates. ${ }^{47}$ In addition, the midluteal endometrial pattern of women with unexplained infertility is related to the chance of pregnancy. The pregnancy rate is significantly higher when the endometrium 
displays a homogenous hyperechogenic pattern comparatively with nonhomogeneous pattern. ${ }^{48}$ Endometrial pattern and thickness were not predictive of pregnancy outcomes in oocyte donation cycles, both prior and following progesterone administration. ${ }^{49}$ However, in frozen embryo transfers, it was showed that an increase in progesterone dosage when there is not a mid luteal nonhomogeneous pattern could lead an increased pregnancy rate. ${ }^{50}$

\section{Uterine Doppler}

Doppler studies have demonstrated that the resistance of uterine and endometrial arteries decreases significantly during the mesoluteal phase, i.e. in the period of embryo implantation. ${ }^{51-57}$ It is probable that these vascular changes play a significant role in the implantation process because they are present from the beginning of the embryo nidation. In rodents, it has been proven an increase of the capillary permeability 24 hours before the blastocyst endometrium contact that takes place at the invasion site due to the local mediation of prostaglandins. ${ }^{58}$ Between the 6 and 12 postovulatory days the endometrium capillaries experience a progressive dilation acquiring a sinusoidal appearance, while the syncytiotrophoblast invades the endometrium. Around the 11 to 12 day, the uteroplacental circulation is fully established when maternal blood flows into syncytiotrophoblast lacunae. ${ }^{59}$

Goswany, Williams and Steptoe ${ }^{60}$ demonstrated that the blood flow in the uterine arteries determines IVF success and that the uterine receptivity improved by increasing the vascular perfusion with HRT. Despite of the many studies that have been published since, there is no consensus on the importance of Doppler studies of these arteries in ART (Fig. 4). A substantial group of authors found significant differences in uterine arteries resistance between cycles with or without pregnancy, yet another important group does not observe this. ${ }^{61}$ These contradictory results are due to significant methodological variations, such as the ovarian stimulation protocol used, the cycle's day when the Doppler study was carried out or the sonographic examination route. $^{61}$

Optimal uterine receptivity seems to occur when the mean pulsatility index of both arteries ranges between 2 and 3, ${ }^{62-64}$ the implantation and pregnancy rates significantly decreasing when pulsatility is over three or four ${ }^{62-70}$ or when diastolic flow is absent in the Doppler waveform. ${ }^{69,70}$ These limits have been proposed as a clinical marker to indicate the convenience to transfer or not the embryo. In doing so, its ability to predict uterine receptivity presents high sensitivity (96-100\%) and a high negative predictive value (88-100\%) although it has low specificity

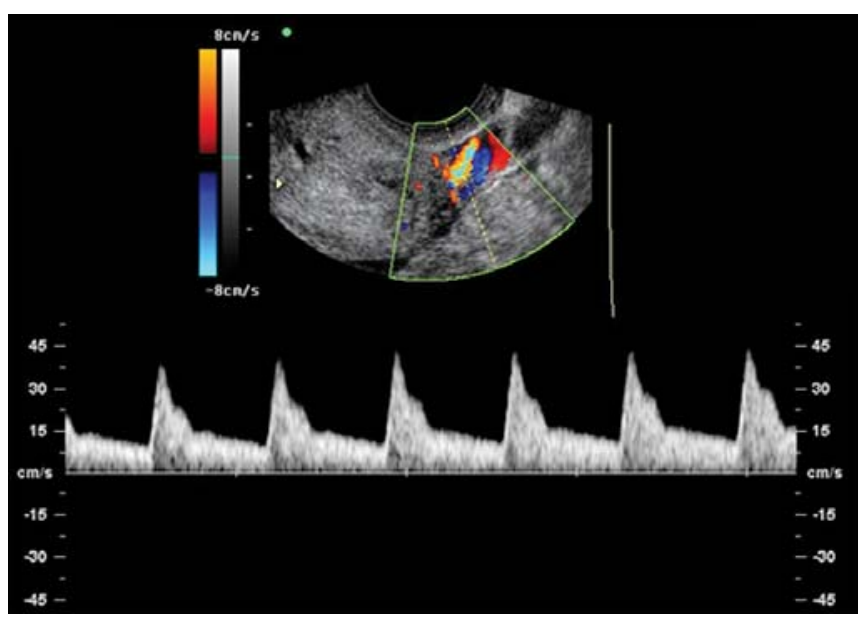

Fig. 4: Flow velocity waveform of uterine artery on the day of hCG administration

(13-35\%) and positive predictive value $(44-56 \%)^{10}$ (Table 1). Inadequate blood flow would thus prevent implantation, although optimal uterine perfusion does not always imply pregnancy. In addition to this, high uterine resistance is observed in less than $10 \%$ of nonconception cycles, suggesting that this parameter is responsible for implantation failure in very few cases. ${ }^{71}$

The relationship between uterine Doppler, endometrial and subendometrial blood flow assessed by 3D power Doppler angiography during stimulated and natural cycles has been evaluated. Several authors conclude that uterine Doppler is a poor reflection of subendometrial blood flow and its measurement cannot represent endometrial blood flow during stimulated cycles. ${ }^{72}$

\section{D and 3D Endometrial Doppler}

Endometrial Doppler should reflect more appropriately the endometrial perfusion and uterine receptivity because the endometrium is the place where implantation occurs. Uterine and endometrial blood flows perform in a similar way during the menstrual cycle. Nevertheless, they show a weak correlation when evaluated by velocimetric indices. ${ }^{73}$ During the luteal phase, the vascular endothelial growth factor (VEGF) expression is increased in the endometrium $^{74,75}$ and there is a greater angiogenic activity. ${ }^{76}$ Recently, a close relationship between a strong VEGF expression in the endometrium and a successful outcome of implantation has been demonstrated. ${ }^{77}$

Doppler study allows us to evaluate endometrial blood flow by means of analyzing flow velocity waveforms of subendometrial and endometrial arteries ${ }^{78-85}$ and the color mapping by $2 \mathrm{D}^{79,81,86-89}$ or $3 \mathrm{D}$ ultrasound. ${ }^{28-32,90-92}$

Vascular resistance in the endometrial spiral arteries or the subendometrial radial arteries (Fig. 5), also called 


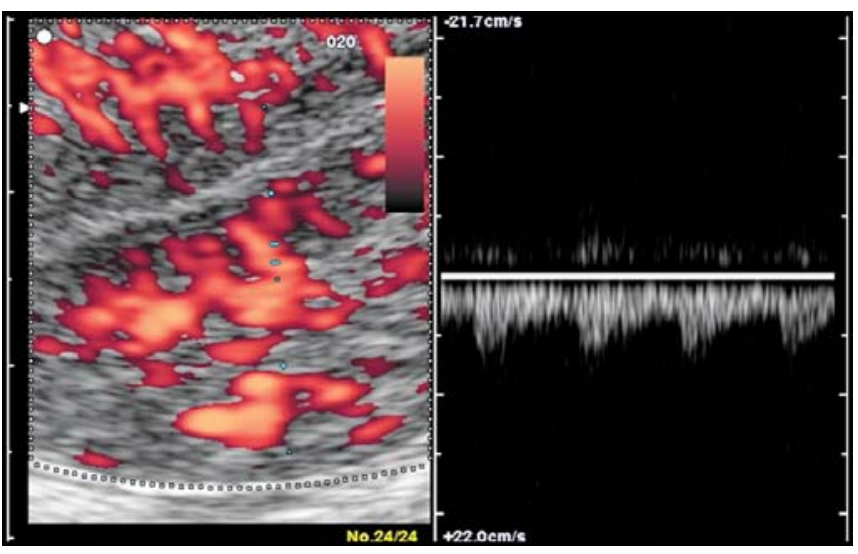

Fig. 5: Flow velocity waveform of subendometrial-endometrial arteries on $\mathrm{hCG}$ administration day

intramyometrial subendometrial arteries, ${ }^{56,61,80}$ is found to be decreased on the day of oocyte retrieval or ET in patients who achieve pregnancy, ${ }^{28,81,84,85}$ although every author cannot find it. ${ }^{79,82,83}$ In an intrauterine insemination program, ${ }^{80}$ we observed that the peak systolic velocity of the dominant uterine artery was significantly higher in the midluteal phase in the cycles in which pregnancy was achieved. Moreover, subendometrial radial arteries pulsatility was the only parameter that improved in those cycles where pregnancy was achieved after a previous nonconceptional cycle, except when implantation failed and subsequently a miscarriage or ectopic pregnancy was diagnosed. ${ }^{61,80}$

Color mapping of endometrial vascularity can be classified in various types according to the degree of penetration into the endometrial thickness, using conventional color ${ }^{79,81,87}$ or power Doppler. ${ }^{86,87}$ In this way we differentiate four types of endometrial blood flow:

- Type 0 or negative flow, when only the surrounding myometrial vessels are seen nonreaching the endometrium

- Type I or peripheral flow, if the color signal reaches the hyperechogenic outer layer of the endometrium

- Type II or intermediate, when color mapping fills in the outer half of the endometrial hypoechogenic thickness; and

- Type III or central flow, if the vessels reach the endometrial cavity invading the entire endometrial thickness (Figs 6A and B).

It has been proposed that the endometrial and subendometrial area should be taken as a unity when the uterine perfusion is assessed by color Doppler, since there is no difference between the endometrial and subendometrial blood flow regarding to the possibility of achieving pregnancy. ${ }^{88}$ Nevertheless, color mapping is directly related to the sensitivity of the equipment and the adequate angle
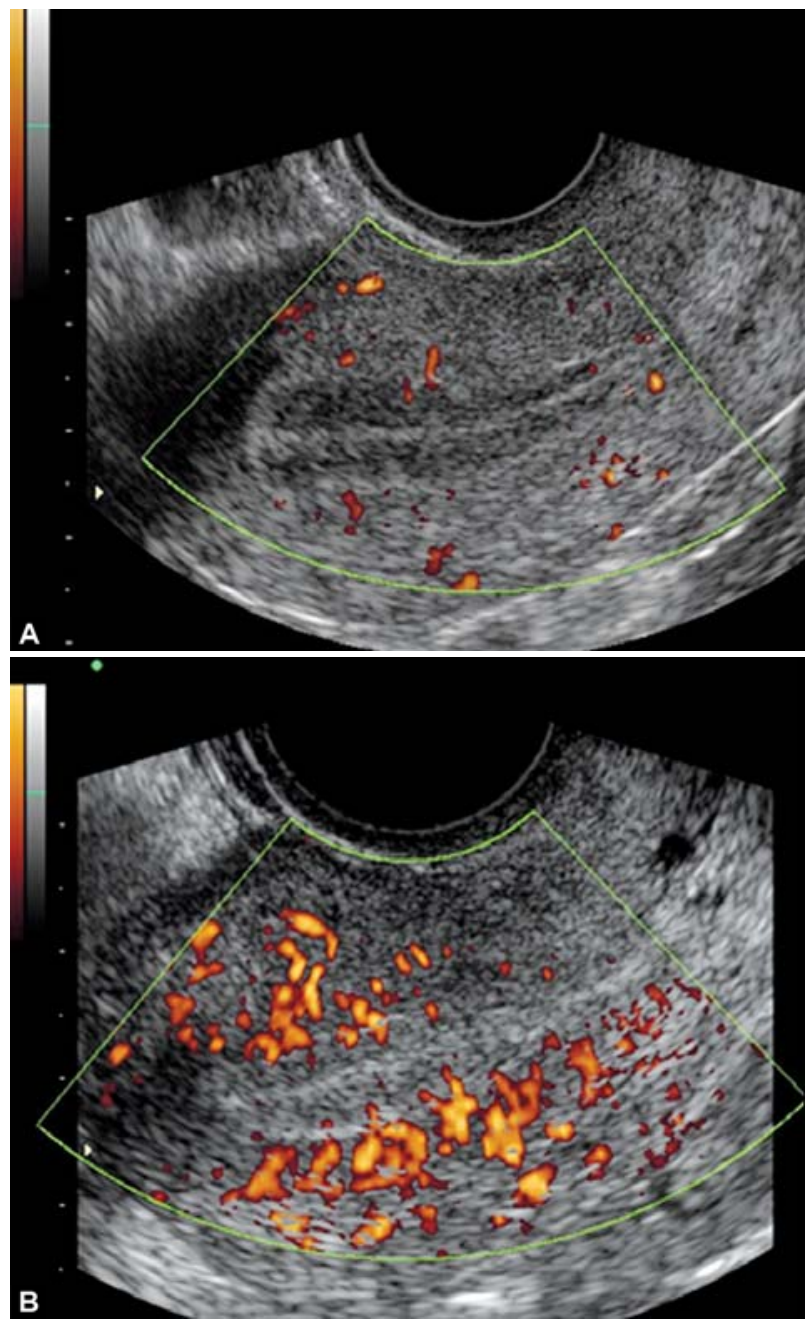

Figs 6 A and $B$ : $(A)$ Endometrial power Doppler mapping type 0 in which only myometrial vessels can be seen without reaching the subendometrial halo; (B) Endometrial amplitude mapping type II when color signal reaches the endometrial cavity

of insonation applied, so it is very important to always use the same characteristics, especially when recording the minimum velocity. For this reason, power Doppler is more reliable because signal amplitude mapping detects lower blood flow velocities and is unaffected by the angle of insonation. In general, endometrial color mapping has been evaluated in a subjective way although the color area can also be quantified. ${ }^{89}$

The absence of color mapping of the endometrium and subendometrial areas means an absolute implantation failure $^{79,85}$ or a significant decrease ${ }^{88}$ of the implantation rate. Conversely, the pregnancy rate increases when the vessels reach the subendometrial halo and endometrium. ${ }^{79,88}$ The presence of vessels within the endometrium is associated with a thicker endometrium, which suggests a correlation between the endometrial perfusion and endometrial growth. ${ }^{88}$ On the other hand, the absence of endometrial-subendometrial blood flow is accompanied by a high uterine artery resistance. ${ }^{88}$ Women with a higher 
endometrial flow area by power Doppler study have a greater probability of pregnancy, whereas below $5 \mathrm{~mm}^{2}$ it is difficult that implantation will take place even with an adequate endometrial thickness. ${ }^{89}$ We have not found significant differences in endometrial thickness, uterine and endometrial blood flow between conception and nonconception cycles after intrauterine insemination. On the contrary, all these parameters present higher values on the day of hCG administration in these cycles that achieve pregnancy by IVF. Nevertheless, only endometrial thickness and the uterine implantation index combining ultrasound and Doppler parameters show significant differences (Table 4). When pregnancy is achieved but endometrialsubendometrial flow on the day of ET cannot be seen, more than a half of these pregnancies will end in spontaneous miscarriage. ${ }^{88}$ This suggests that the development of the endometrial vascular network should be important for the support of the first stages of pregnancy.

As mentioned above, three-dimensional ultrasound allows studying not only the endometrial volume but also the complete endometrial perfusion (Fig. 7A). A specific software named VOCAL performs an automatic

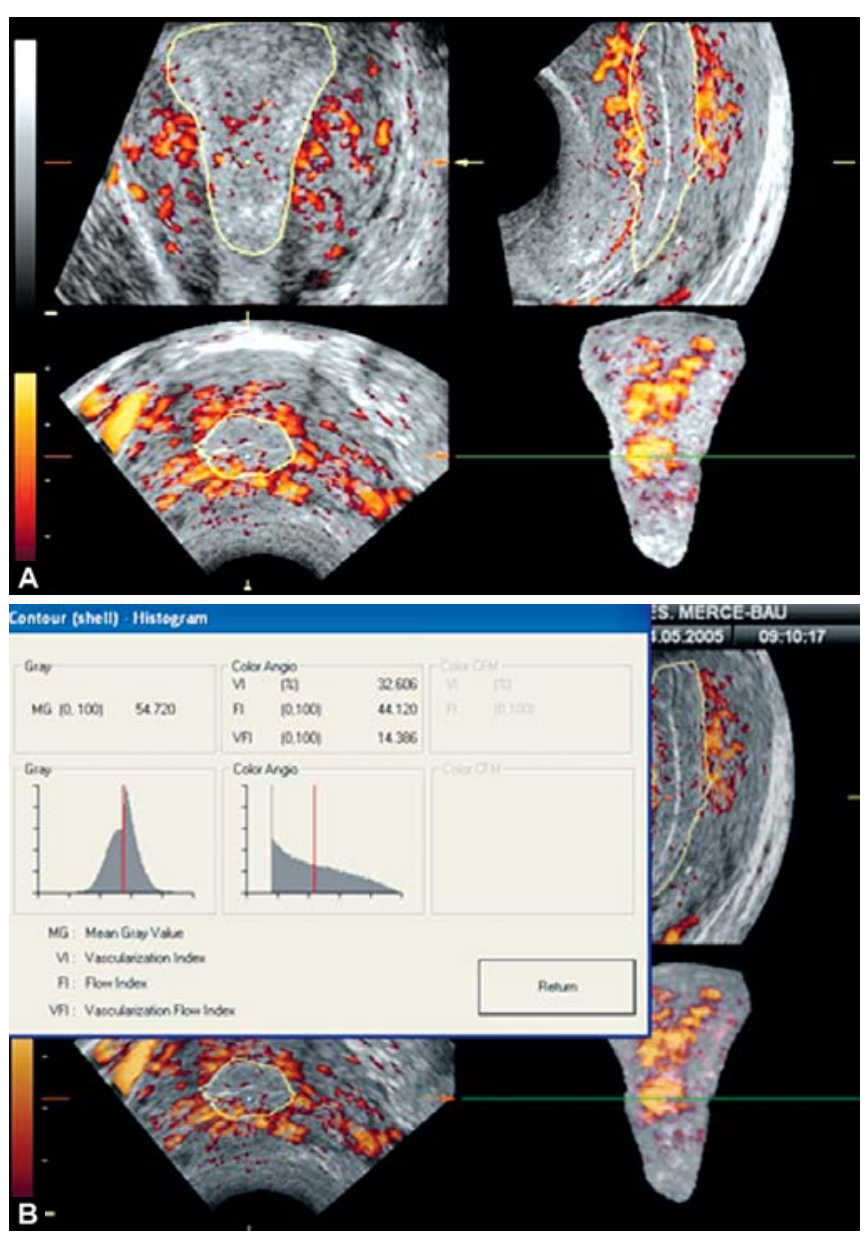

Figs 7A and B: (A) Three-dimensional power Doppler acquisition of endometrial vascularity on hCG administration day in an IVF cycle; (B) Power Doppler indices quantification by VOCAL software quantification of endometrial vascularization by three 3D power Doppler indices. ${ }^{93}$ The vascularization index (VI) estimates the number of color voxels inside the endometrial volume, thus expressing the number of endometrial blood vessels as a percentage. The flow index (FI) is the average color value from all the color voxels, depicting the mean intensity of the endometrial blood flow. The vascularization flow Index (VFI) is the average color value out of all the color and gray voxels, meaning the vascularization as well as the blood flow, in other words, the perfusion inside the endometrium (Fig. 7B). ${ }^{93}$

Endometrial 3D power Doppler indices change significantly during the normal menstrual cycle. These vascularity indices increase during the proliferative phase reaching a maximum 2 to 3 days before ovulation. From this peak, vascularity indices decrease to reach a nadir 2 to 5 days after ovulation. Afterwards, endometrial vascular indices increase progressively along the rest of the luteal phase. Subendometrial blood flow experiences parallel changes but shows higher values of the vascularity indices. ${ }^{24,94}$ A reduced endometrial blood flow after ovulation could be related to an increased uterine contractility $^{95}$ and may lead to endometrial hypoxia during the implantation period. ${ }^{96}$

Endometrial and subendometrial blood flows assessed in the same patients by 3D power Doppler indices are significantly lower in stimulated than in natural cycles. ${ }^{97}$ It has also been reported that endometrial and subendometrial blood flows are negatively affected by serum estradiol concentrations, but they are not affected by other factors, such as women age, smoking habits, or types of infertility or parity, during IVF treatment. ${ }^{98}$ This fact could explain that ovarian hyper-responders tend to have lower endometrial and subendometrial blood flows during the early luteal phase (+2 hCG day). ${ }^{99}$ We have observed that endometrial FI is significantly decreased after pituitary suppression with a long GnRH protocol. Endometrial vascularity indices on the day of hCG administration do not show statistical differences between single and multifollicular ovarian development. Midluteal endometrial blood flow is found to be lower than preovulatory endometrial blood flow but differences do not reach statistical significance (Figs 2B to D). Small intramural fibroids do not seem to affect the endometrial and subendometrial blood flow; ${ }^{100}$ on the other hand, patients with hydrosalpinx show a decreased endometrial and subendometrial blood flow. ${ }^{101}$

Even though most authors assess both endometrial and subendometrial vascularization as a pregnancy predictor, ${ }^{28-}$ $31,90,91$ we prefer to calculate only the 3D power Doppler indices of the endometrium. ${ }^{32}$ There are three reasons that account for this decision: 
Table 4: Uterine receptivity parameters on the day of hCG administration in an intrauterine insemination and IVF cycles ${ }^{1}$

\begin{tabular}{|c|c|c|c|c|c|c|}
\hline \multirow[t]{2}{*}{ Parameters } & \multicolumn{2}{|c|}{ IIU } & \multirow[t]{2}{*}{$P$} & \multicolumn{2}{|c|}{ IVF } & \multirow[t]{2}{*}{$p$} \\
\hline & $\begin{array}{c}\text { Pregnant } \\
(n=10)\end{array}$ & $\begin{array}{c}\text { Nonpregnant } \\
(n=40)\end{array}$ & & $\begin{array}{c}\text { Pregnant } \\
(n=10)\end{array}$ & $\begin{array}{c}\text { Nonpregnant } \\
(n=22)\end{array}$ & \\
\hline ET & $10.0 \pm 2.8$ & $10.3 \pm 2.3$ & ns & $14.4 \pm 3.1$ & $12.1 \pm 2.0$ & 0.02 \\
\hline UPI & $2.18 \pm 0.81$ & $2.65 \pm 0.93$ & ns & $2.18 \pm 0.49$ & $2.21 \pm 0.44$ & ns \\
\hline EF & $1.4 \pm 0.9$ & $1.5 \pm 1.3$ & ns & $3.1 \pm 1.2$ & $2.2 \pm 1.4$ & ns \\
\hline UMI & $17 \pm 15$ & $18 \pm 17$ & ns & $46 \pm 18$ & $29 \pm 17$ & 0.01 \\
\hline
\end{tabular}

(1) Values indicate mean \pm SD; ET: Endometrial thickness in $\mathrm{mm}$; UPI: Mean pulsatility index of both uterine arteries; EF: Endometrial blood flow evaluated by power Doppler mapping according to the following 'scoring system': absent, only miometrial (Type 0$)=0$; Peripheral $($ Type I $)=1$; Intermediate $($ Type II $=2$; Central (Type III) = 4; UMI: Uterine implantation index according to formula (ET x EF) + [ EMP/UPI-notch], where ET is the endometrial thickness in mm, EF: Endometrial flow according to the explained scoring system; EMP: Endomiometrial pattern, whose value is calculated by adding the endometrial pattern score (triple line $=3$; other types $=0$ ) and miometrial pattern (homogeneous $=1$; nonhomogeneous $=0$ ); UPI value is the mean pulsatility index of both uterine arteries and uterine 'notch' is pointed as present $(0)$ or absent. ${ }^{1}$

Table 5: ROC analysis of 3D endometrial volume and power Doppler indices for predicting pregnancy in IVF/ICSI cycles according to number of Grade 1 embryos transferred

\begin{tabular}{|c|c|c|c|c|c|c|}
\hline \multirow[b]{2}{*}{ Parameters } & \multicolumn{3}{|c|}{ No G1 or 1 G1 embryos transferred $(n=43)$} & \multicolumn{3}{|c|}{ > 1 G1 embryos transferred $(n=34)$} \\
\hline & $\begin{array}{l}\text { Area under } \\
\text { curve }\end{array}$ & $95 \% \mathrm{Cl}^{*}$ & $p$ & $\begin{array}{l}\text { Area under } \\
\text { curve }\end{array}$ & $95 \% \mathrm{Cl}^{*}$ & $p$ \\
\hline Endometrial volume (ml) & 0.75 & $0.60-0.90$ & 0.01 & 0.60 & $0.38-0.81$ & 0.38 \\
\hline Vascularization index & 0.72 & $0.56-0.89$ & 0.02 & 0.42 & $0.21-0.63$ & 0.47 \\
\hline Flow index & 0.83 & $0.68-0.97$ & 0.001 & 0.65 & $0.43-0.86$ & 0.19 \\
\hline Vascularization flow index & 0.80 & $0.65-0.95$ & 0.002 & 0.34 & $0.16-0.53$ & 0.15 \\
\hline
\end{tabular}

* $95 \%$ confidence interval

1. The endometrium is the actual place where implantation occurs.

2. Subendometrial vascularization experiences the same changes as the endometrial one but with higher vascularity indices.

3. It is not possible to determine the subendometrial space accurately as it has been defined as an outer shell surrounding the endometrium with many different thicknesses- $10 \mathrm{~mm},{ }^{30} 5 \mathrm{~mm}^{28,29}$ or $1 \mathrm{~mm}^{31}$

The uterine wall thickness varies from patient to patient, so if we apply the same shell thickness, the vessels in the subendometrial zone will vary greatly from patient to patient, diminishing the reliability of the results. The only way to accurately define the subendometrial space would be applying a single percentage for the various thicknesses of the uterine wall. Furthermore, the endometrial vascularization is well defined as it is, within the limits of the myoendometrial junction.

Some authors have proved that subendometrial vascularity indices may behave as predicting factors for pregnancy on the transfer day ${ }^{28}$ and the day of hCG administration. ${ }^{29,32}$ Others cannot prove 3D power Doppler indices to be good predictors for pregnancy after folliclestimulating hormone (FSH) stimulation ${ }^{30}$ or in the oocyte retrieval day. ${ }^{31}$ Recently it has been proposed the day of hCG administration as the best day to evaluate the uterine receptivity ${ }^{84}$ In frozen-thawed ET cycles, endometrial and subendometrial vascularity measured by 3D power Doppler ultrasound is not a good predictor of pregnancy if measured at one time point only..$^{90,92}$ On the contrary, endometrial and subendometrial power Doppler indices are significantly higher in pregnant patients with live following stimulated IVF and frozen thawed-ET transfer than those who suffered miscarriage. $^{91}$

Our results out of 80 infertile women undergoing a first IVF-ICSI cycle show significantly increased endometrial indices of vascularization flow on the hCG day in the pregnant group (Table 3). ${ }^{32}$ In addition, the ability of 3D parameters for pregnancy prediction seems to depend on the quality of the embryos transferred. When two or three grade embryos were transferred, the area under the receiver operating characteristic (ROC) curve of the endometrial volume and the endometrial vascularity indices was inferior to 0.65 , although with no statistical significance. On the other hand, when none or only one grade 1 embryo was transferred, the ROC curve showed a significant area for all the parameters, being slightly greater for FI. A FI greater than or equal to 26.1 predicted gestation with a sensitivity 
of $85.7 \%$ and a $27.6 \%$ false-positive rate (Table 5). The ROC analysis also demonstrated that the endometrial volume and 3D power Doppler indices predict significantly which pregnancies will carry on normally; however, no relationship with the possibility of multiple gestations has been found.

According to our results it can be assumed that the 3D sonographic and power Doppler implantation markers are specially related to pregnancy when the quality of the transferred embryos is not good enough or only one top embryo can be transferred. Therefore, in order to achieve a pregnancy, a good endometrial receptivity, as assessed by ultrasound markers, seems essential when only one top quality embryo is available for transfer. The majority of ET policies propose a reduced number of embryos to be transferred $^{102,103}$ and the amount of cycles where only one embryo is transferred is progressively increasing. ${ }^{104,105} \mathrm{At}$ this point, we believe that the new $3 \mathrm{D}$ markers of endometrial receptivity could be useful to select the more suitable cycle for the transfer of a single embryo.

\section{REFERENCES}

1. Mercé LT. Ultrasound markers of implantation. Ultrasound Rev Obstet Gynecol 2002;2(2):110-23.

2. Fanchin R. Assessing uterine receptivity in 2001: ultrasonographic glances at the New Millennium. Ann NY Acad Sci 2001;943:185-202.

3. Mercé LT. Ultrasound markers of implantation. In: Kurjak A, Chervenak FA (Eds). Donald School Textbook of Ultrasound in Obstetrics and Gynecology. New Delhi: Jaypee Brothers Medical Publishers; 2004;691-700.

4. Imoedemhe DA, Shaw RW, Kirkland A, et al. Ultrasound measurement of endometrial thickness on different ovarian stimulation regimens during in vitro fertilization. Hum Reprod 1987;2(7):545-47.

5. Tan SL, Biljan MM. Selection of candidates for in vitro fertilization based on color Doppler findings. In: Kupesic S, De Ziegler D (Eds). Ultrasound and Infertility. London: The Parthenon Publishing Group 2000;155-68.

6. Li TC, Nuttall L, Klentzeris L, et al. How well does ultrasonographic measurement of endometrial thickness predict the results of histological dating? Hum Reprod 1992;7(1):1-5.

7. Bassil S. Changes in endometrial thickness, width, length and pattern in predicting pregnancy outcome during ovarian stimulation in in vitro fertilization. Ultrasound Obstet Gynecol 2001;18(3):258-63.

8. Rabinowitz R, Laufer N, Lewin A, et al. The value of endometrial measurement in the prediction of pregnancy following in vitro fertilization. Fertil Steril 1986;45(6):824-28.

9. Khalifa E, Brzyski RG, Oehninger S, et al. Sonographic appearance of the endometrium: The predictive value for the outcome of in vitro fertilization in stimulated cycles. Hum Reprod 1992;7(5):677-80.

10. Friedler S, Schenker JG, Herman A, et al. The role of ultrasonography in the evaluation of endometrial receptivity following assisted reproduction treatments: A critical review. Hum Reprod Update 1996;2(4):323-35.
11. Leibovitz Z, Grinin V, Rabia R, et al. Assessment of endometrial receptivity for gestation in patients undergoing in vitro fertilization, using endometrial thickness and the endometriummyometrium relative echogenicity coefficient. Ultrasound Obstet Gynecol 1999;14(3):194-99.

12. Weissman A, Gotlieb L, Casper RF. The detrimental effect of increased endometrial thickness on implantation and pregnancy rates and outcome in an in vitro fertilization program. Fertil Steril 1999;71(1):147-49.

13. Dietterich C, Check JH, Choe JK, et al. Increased endometrial thickness on the day of human chorionic gonadotropin (hCG) injection does not adversely effect pregnancy or implantation rates following in vitro fertilization-embryo transfer (IVF-ET). Fertil Steril 2002;77(4):781-86.

14. Zhang $\mathrm{X}$, Chen $\mathrm{CH}$, Confino $\mathrm{E}$, et al. Increased endometrial thickness is associated with improved treatment outcome for selected patients undergoing in vitro fertilization-embryo transfer. Fertil Steril 2005;83(2):336-40.

15. Dickey RP, Olar TT, Curole DN, et al. Endometrial pattern and thickness associated with pregnancy outcome after assisted reproduction technologies. Hum Reprod 1992;7(3):418-21.

16. Noyes N, Hampton BS, Berkeley A, et al. Factors useful in predicting the success of oocyte donation: A 3-year retrospective analysis. Fertil Steril 2001;76(1):92-97.

17. Remohí J, Ardiles G, García-Velasco, et al. Endometrial thickness and serum oestradiol concentrations as predictors of outcome in oocyte donation. Hum Reprod 1997;12(10): 2271-76.

18. Kovacs P, Matyas S, Boda K, et al. The effect of endometrial thickness on IVF/ICS outcome. Hum Reprod 2003;18(11): 2337-41.

19. Richter KS, Bugge KR, Bromer JG, et al. Relationship between endometrial thickness and embryo implantation, based on 1,294 cycles of in vitro fertilization with transfer of two blastocyststage embryos. Fertil Steril 2007;87(1):53-59.

20. Alcázar JL, Mercé LT, García-Manero M, et al. Endometrial volume and vascularity measurements by transvaginal 3-dimensional utrasonography and power Doppler angiography in stimulated and tumoral endometria. An interobserver reproducibility study. J Ultrasound Med 2005;24(8):1091-98.

21. Mercé LT, Alcázar JL, Engels V, et al. Endometrial volume and vascularity measurements by transvaginal three-dimensional ultrasonography and power Doppler angiography in stimulated and tumoral endometria: Intraobserver reproducibility. Gynecol Oncol 2006;100(3):544-50.

22. Lee A, Sator M, Ktatochwil A, et al. Endometrial volume change during spontaneous menstrual cycles: volumetry by transvaginal three-dimensional ultrasound. Fertil Steril 1997;68(5):831-35.

23. Raine-Fenning N, Campbell BK, Clewes JS, et al. Defining endometrial growth during the menstrual cycle with threedimesnional ultrasound. Br J Obstet Gynaecol 2004;111(9): 944-49.

24. Jokubkiene L, Sladkevicius P, Rovas L, et al. Assessment of changes in endometrial and subendometrial volume and vascularity during the normal menstrual cycle using threedimensional power Doppler ultrasound. Ultrasound Obstet Gynecol 2006;27(6):672-79.

25. Raga F, Bonilla-Musoles F, Casan EM, et al. Assessment of endometrial volume by three-dimensional ultrasound prior to embryo transfer: Clues to endometrial receptivity. Hum Reprod 1999;14(11):2851-54. 
26. Zollner U, Zollner KP, Specketer MT, et al. Endometrial volume as assessed by three-dimensional ultrasound is a predictor of pregnancy outcome after in vitro fertilization and embryo transfer. Fertil Steril 2003;80(6):1515-17.

27. Schild Rl, Indefrei D, Eschweiler S, et al. Three-dimensional endometrial volume calculation and pregnancy rate in an in vitro fertilization programme. Hum Reprod 1999;14(5):1255-58.

28. Kupesic S, Bekavac I, Bjelos D, et al. Assessment of endometrial receptivity by transvaginal color Doppler and three-dimensional power Doppler ultrasonography in patients undergoing in vitro fertilization procedures. J Ultrasound Med 2001;20(2):125-34.

29. Wu HM, Chiang CH, Huang HY, et al. Detection of the subendometrial vascularization flow index by three-dimensional ultrasound may be useful for predicting the pregnancy rate for patients undergoing in vitro fertilization-embryo transfer. Fertil Steril 2003;79(3):507-11.

30. Järvelä IY, Sladkevicius P, Nelly S, et al. Evaluation of endometrial receptivity during in vitro fertilization using threedimensional power Doppler ultrasound. Ultrasound Obstet Gynecol 2005;26(7):765-69.

31. Ng EH, Chan CC, Tang OS, et al. The role of endometrial and subendometrial blood flows measured by three-dimensional power Doppler ultrasound in the prediction of pregnancy during IVF treatment. Hum Reprod 2006;21(1):164-70.

32. Mercé LT, Barco MJ, Bau S, et al. Are endometrial parameters by three-dimensional ultrasound and power Doppler angiography related to in vitro fertilization/embryo transfer outcome? Fertil Steril 2008;89(1):111-17.

33. Turnbull LW, Rice CF, Horsman A, et al. Magnetic resonance imaging and transvaginal ultrasound of the uterus prior to embryo transfer. Hum Reprod 1994;9(12):2438-43.

34. Grunfeld L, Walker B, Bergh PA, et al. High-resolution endovaginal ultrasonography of the endometrium: a noninvasive test for endometrial adequacy. Obstet Gynecol 1991;78(2):200-04.

35. Parsons AK, Parada C, Parsons M, et al. Ultrasound correlation with endometrial histology. Gynecologic investigation, 38th Annual Meeting, San Antonio, Texas, March 20-23, 1991;Abstract 560;378.

36. Fanchin R, Righini C, Ayoubi JM, et al. New look at endometrial echogenicity: objective computer-assisted measurements predict endometrial receptivity in in vitro fertilization-embryo transfer. Fertil Steril 2000;74(2):274-81.

37. Bakos $\mathrm{O}$, Lundvist $\mathrm{O}$, Bergh T. Transvaginal sonographic evaluation of endometrial growth and texture in spontaneous ovulatory cycles a descriptive study. Hum Reprod. 1993;8(6):799-806.

38. Tang B, Gurpide E. Direct effect of gonadotropins on decidualization of human endometrial stroma cells. J Steroid Biochem Mol Biol. 1993;47(1-6):115-21.

39. De Ziegler D, Fanchin R. Endometrial receptivity in controlled ovarian hyperstimulation $(\mathrm{COH})$ : the hormonal factor. In: Bulletti C, Gurpide E, Flagmini C (Eds). The Human Endometrium. Ann NY Acad Sci 1994;734:209-20.

40. Tetlow RL, Richmond I, Manton DJ, et al. Histological analysis of the uterine junctional zone as seen by transvaginal ultrasound. Ultrasound Obstet Gynecol. 1999;14(3):188-93.

41. Smith B, Porter R, Ahuja K, et al. Ultrasonic assessment of endometrial changes in stimulated cycles an in vitro fertilization and embryo transfer program. J In Vitro Fert Embryo Transf 1984;1(4):233-38.
42. Gonen Y, Casper RF. Prediction of implantation by the sonographic appearance of the endometrium during controlled ovarian stimulation for in vitro fertilization (IVF). J In Vitro Fert Embryo Trans 1990;7(3):146-52.

43. Sher G, Herbert C, Maassarani G, et al. Assessment of the late proliferative phase endometrium by ultrasonography in patients undergoing in vitro fertilization and embryo transfer (IVF/ET). Hum Reprod 1991;6(2):232-37.

44. Leibovitz ZS, Degani R, Rabia R. Endometrium-to-myometrium relative echogenicity coefficient. A new sonographic approach for the quantitative assessment of endometrial echogenicity. Gynecol Obstet Invest 1998;45(2):121-25.

45. Detti L, Yelian FD, Krugger ML, et al. Endometrial thickness dynamics and morphologic characteristics during pituitary downregulation with antagonists in assisted reproductive technology cycles. J Ultrasound Med 2008;27(11);1591-96.

46. Chen SL, Wu FR, Luo C, et al. Combined analysis of endometrial thickness and pattern in predicting outcome of in vitro fertilization and embryo transfer: a retrospective cohort study. Reprod Biol Endocrinol 2010;24(8):30.

47. Check JH, Dietterich C, Lurie D. Non-homogeneous hyperechogenic pattern 3 days after embryo transfer is associated with lower pregnancy rates. Hum Reprod 2000;15(5):1069-74.

48. Check JH, Gandica R, Dietterich C, et al. Evaluation of a nonhomogeneous endometrial echo pattern in the midluteal phase as a potential factor associated with unexplained infertility. Fertil Steril 2003;79(3):590-93.

49. Barker MA, Boehnlein LM, Kovacs P, et al. Follicular and luteal phase endometrial thickness and echogenic pattern and pregnancy outcome in oocyte donation cycles. J Assist Reprod Genet 2009;26:243-49.

50. Check JH, Dietterich C, Cohen R, et al. Increasing the dosage of progesterone $(\mathrm{P})$ supplemention from mid-luteal phase in women not attaining a mid-luteal homegenous hyperechogenic (HH) pattern with sonography improves pregnancy rates (PRS) following frozen embryo transfer. Clin Exp Obstet Gynecol 2010;37(1):13-14.

51. Scholtes MCW, Wladimiroff JW, Van Rijen HJM, et al. Uterine and ovarian flow velocity waveforms in the normal menstrual cycle: A transvaginal study. Fertil Steril 1989;52(6):981-85.

52. Sladkevicius P, Valentin L, Marsál K. Blood flow velocity in the uterine and ovarian arteries during the normal menstrual cycle. Ultrasound Obstet Gynecol 1993;3(3):199-208.

53. Tan SL, Zaidi J, Campbell S, et al. Blood flow changes in the ovarian and uterine arteries during the normal menstrual cycle. Am J Obstet Gynecol 1996;175(3 Pt 1):625-31.

54. Bourne TH, Hagström HG, Granberg S, et al. Ultrasound studies of vascular and morphological changes in the human uterus after a positive self-test for the urinary luteinizing hormone surge. Hum Reprod 1996;11(2):369-75.

55. Agrawal R, Conway GS, Sladkevicius P, et al. Serum vascular endothelial growth factor (VEGF) in the normal menstrual cycle: Association with changes in ovarian and uterine Doppler blood flow. Clin Endocrinol (Oxf) 1999;50(1):101-06.

56. Mercé LT. Doppler de los cambios ováricos y endometriales preimplantatorios. In: Kurjak A, Carrera JM (Eds). Ecografía en Medicina Materno-Fetal. Barcelona: Masson 2000;87-104.

57. Kupesic S, Mercé LT, Zodan T, et al. Normal and abnormal corpus luteum function. In: Kupesic S, de Ziegler D (Eds). Ultrasound and Infertility. Lancs: The Parthenon Publishing Group 2000;67-76. 
58. Psychoyos A, Martel D. Embryo-endometrial interactions at implantation. In: Edwards RG, Purdy JM, Steptoe PC (Eds). Implantation of the Human Embryo. London: Academic Press 1985;197-219.

59. Czyba JC, Montella A. Les deux premieres semaines du developpemnet embryonnaire. In: Czyba JC, Montella A (Eds). Biologie De La Reproduction Humaine. Montpellier: Sauramps Medical 1993;217-28.

60. Goswany RK, Williams G, Steptoe PC. Decreased uterine perfusion: A cause of infertility. Hum Reprod 1988;3(8): 955-59.

61. Mercé LT. Estudio Doppler de la implantación y placentación inicial. In: Kurjak A, Carrera JM (Eds). Ecografía en Medicina Materno-Fetal. Barcelona: Masson 2000;113-36.

62. Steer CV, Campbell S, Tan SL, et al. The use of transvaginal color flow imaging after in vitro fertilization to identify optimum uterine conditions before embryo transfer. Fertil Steril 1992;57(2):372-76.

63. Zaidi J, Pittrof R, Shaker A, et al. Assessment of uterine artery blood flow on the day of human chorionic gonadotropin administration by transvaginal color Doppler ultrasound in an in vitro fertilization program. Fertil Steril 1996;65(2):377-81.

64. Tsai YC, Chang JC, Tai MJ, et al. Relationship of uterine perfusion to outcome of intrauterine insemination. J Ultrasound Med 1996;15(9):633-36.

65. Coulam CB, Bustillo M, Soenksen DM, et al. Ultrasonographic predictors of implantation after assisted reproduction. Fertil Steril 1994;62(5):1004-10.

66. Coulam CB, Stern JJ, Soenksen DM, et al. Comparison of pulsatility indexes on the day of oocyte retrieval and embryo transfer. Hum Reprod 1995;10(1):82-84.

67. Bustillo M, Krysa LW, Coulam CB. Uterine receptivity in an oocyte donation programme. Hum Reprod 1995;10(2): 442-45.

68. Favre R, Bettahar K, Grange G, et al. Predictive value of transvaginal uterine Doppler assessment in an in vitro fertilization program. Ultrasound Obstet Gynecol 1993;3(5): 350-53.

69. Tekay A, Martikainen H, Jouppila P. The clinical value of transvaginal colour Doppler ultrasound in assisted reproductive technology procedures. Hum Reprod 1996;11:1589-91.

70. Deichert U, Albrand-Thielman C, Van de Sandt M. Dopplersonographic pelvic blood flow measurements and their prognostic value in terms of luteal phase and implantation. Hum Reprod 1996;11(8):1591-93.

71. Caccitore B, Simberg N, Fusaro P, et al. Transvaginal Doppler study of uterine artery blood flow in in-vitro fertilization-embryo transfer cycles. Fertil Steril 1996;66(1):130-34.

72. Ng EHY, Chan CCW, Tang OS, et al. Relationship between uterine blood flow and endometrial and subendometrial blood flows during stimulated and natural cycles. Fertil Steril. 2006;85(3):721-27.

73. Dickey RP. Doppler ultrasound investigation of uterine and ovarian blood flow in infertility and early pregnancy. Hum Reprod Update 1997;3(5):467-503.

74. Torry DS, Holt VJ, Keenan JA, et al. Vascular endothelial growth factor expression in cycling human endometrium. Fertil Steril 1996;66(1):72-80.

75. Shifren JL, Tseng JF, Zaloudek CJ, et al. Ovarian steroid regulation of vascular endothelial growth factor in the human endometrium; Implications for angiogenesis during the menstrual cycle and in the pathogenesis of endometriosis. J Clin Endocrinol Metab 1996;81(8):3112-28.

76. Rogers P, Abberton K, Susil B. Endothelial cell migratory signal produced by human endometrium during the menstrual cycle. Hum Reprod 1992;7(8):1061-66.

77. Jinno M, Ozaki T, Iwashita M, et al. Measurement of endometrial tissue blood flow: A novel way to assess uterine receptivity for implantation. Fertil Steril 2001;76(6):1168-74.

78. Achiron R, Levran D, Sivan E, et al. Endometrial blood flow response to hormone replacement therapy in women with premature ovarian failure: A transvaginal Doppler study. Fertil Steril 1995;63(3):550-54.

79. Zaidi J, Campbell S, Pittrof R, et al. Endometrial thickness, morphology, vascular penetration and velocimetry in predicting implantation in an in vitro fertilization program. Ultrasound Obstet Gynecol 1995;6(3):191-98.

80. Mercé LT, Moreno C, Bau S. Assessment of luteal and periimplantation blood flow with color Doppler in AIH. In: Abstract book of ESHRE symposium on reproductive medicine. Valencia 1995;12.

81. Battaglia C, Artini PG, Giulini S, et al. Colour Doppler changes and thromboxane production after ovarian stimulation with gonadotrophin-releasing hormone agonist. Hum Reprod. 1997;12(11):2477-82.

82. Yuval Y, Lipitz S, Dor J, et al. The relationships between endometrial thickness, and blood flow and pregnancy rates in in-vitro fertilization. Hum Reprod 1999;14(4):1967-71.

83. Schild RL, Knobloch C, Dorn C, et al. Endometrial receptivity in an in vitro fertilization program as assessed by spiral artery blood flow, endometrial thickness, endometrial volume, and uterine artery blood flow. Fertil Steril 2001;75(2):31-36.

84. Dechaud H, Bessueille E, Bousquet PJ, et al. Optimal timing of ultrasonographic and Doppler evaluation of uterine receptivity to implantation. Reprod Biomed Online 2008;16(3):368-75.

85. Wang L, Qiao J, Li R, et al. Role of endometrial blood flow assessment with color Doppler energy in predicting pregnancy outcome. Reprod Biol Endocrinol 2010;18(8):122.

86. Mercé LT. Aplicaciones del Doppler color en Reproducción. IV Curso Teórico-Práctico sobre Doppler en Ginecología, Obstetricia y Ecocardiografía fetal. Barcelona, de mayo 2002; 2-4.

87. Applebaum M. The menstrual cycle, menopause, ovulation induction, an in vitro fertilization. In: Copel JA, Reed KL (Eds). Doppler Ultrasound In Obstetrics And Gynecology. New York: Raven Press 1995;71-86.

88. Chien LW, Au HK, Chen PL, et al. Assessment of uterine receptivity by the endometrial-subendometrial blood flow distribution pattern in women undergoing in vitro fertilizationembryo transfer. Fertil Steril 2002;78(2):245-51.

89. Yang JH, Wu MY, Chen CD, et al. Association of endometrial blood flow as determined by a modified colour Doppler technique with subsequent outcome of in-vitro fertilization. Hum Reprod 1999;14(6):1606-10.

90. Ng EH, Chan CC, Tang OS, et al.The role of endometrial and subendometrial vascularity measured by three-dimensional power Doppler ultrasound in the prediction of pregnancy during frozen-thawed embryo transfer cycles. Hum Reprod 2006;21(6):1612-17.

91. Ng EH, Chan CC, Tang OS, et al. Endometrial and subendometrial vascularity is higher in pregnant patients with livebirth following ART than in those who suffer a miscarriage. Hum Reprod 2007;22(4):1134-41. 
92. Zácková T, Järvelä IY, Tapanainen JS, et al. Assessment of endometrial and ovarian characteristics using three-dimensional power Doppler ultrasound to predict response in frozen embryo transfer cycles. Reprod Biol Endocrinol 2009;7:151.

93. Mercé LT, Barco MJ, Alcázar JL, et al. Mediciones con la ecografía tridimensional y el programa VOCAL: Cálculo de volúmenes e índices de la angiografía power Doppler. In: Mercé LT (Ed). Manual MISUS: Teoría y Práctica de la Ecografía y Angiografía Doppler Tridimensional en Obstetricia y Ginecología. Madrid: HABE 2006;43-57.

94. Raine-Fenning NJ, Campbell BK, Kendall NR, et al. Quantifying the changes in endometrial vascularity throughout the normal menstrual cycle with three-dimensional power Doppler angiography. Hum Reprod 2004;19(2):330-38.

95. Hauksson A, Akerlund M, Melin P. Uterine blood flow and myometrial activity at menstruation, and the action of vasopressin and a synthetic antagonist. Br J Obstet Gynaecol 1988;95(9):898-904.

96. Fischer B, Bavister BD. Oxygen tension in the oviduct and uterus of rhesus monkeys, hamsters and rabbits. J Reprod Fertil 1993;99(2):673-79.

97. Ng EHY, Chan CCW, Tang OS, et al. Comparison of endometrial and subendometrial blood flow measured by threedimensional power Doppler ultrasound between stimulated and natural cycles in the same patients. Hum Reprod 2004;19(10):2385-90.

98. Ng EHY, Chan CCW, Tang OS, et al. Factors affecting endometrial and subendometrial blood flow measured by threedimensional power Doppler ultrasound during IVF treatment. Hum Reprod 2006;21(4):1062-69.

99. Ng EHY, Chan CCW, Tang OS, et al. Endometrial and subendometrial blood flow measured during early luteal phase by three-dimensional power Doppler ultrasound in excessive ovarian responders. Hum Reprod 2004;19(4):924-31.

100. Ng EHY, Chan CCW, Tang OS, et al. Endometrial and subendometrial blood flow measured by three-dimensional power Doppler ultrasound in patients with small intramural uterine fibroids during IVF treatment. Hum Reprod 2005;20(2):501-06.

101. Ng EHY, Chan CCW, Tang OS, et al. Comparison of endometrial and subendometrial blood flows among patients with and without hydrosalpinx shown on scanning during in vitro fertilization treatment. Fertil Steril 2006;85(2);333-38.

102. American Society of Reproductive Medicine. Practice Committee Report. Guidelines on number of embryos transferred. Release May 2004.

103. ESHRE Task Force on Ethics and Law. Ethical issues related to multiple pregnancies in medically assisted procreation. Hum Reprod 2003;18(9):1976-79.

104. Saldeen P, Sundström P. Would legislation imposing single embryo transfer be a feasible way to reduce the rate of multiple pregnancies after IVF treatment? Hum Reprod 2005;20(1):4-8.

105. De Neubourg D, Gerris J. What about the remaining twins since single-embryo transfer? How far can (should) we go? Hum Reprod 2006;21(4):843-46.

\section{ABOUT THE AUTHORS}

\section{Luis T Mercé}

CENEGO (National Center of Gynecology and Obstetrics US) and Assisted Reproduction Unit. International Ruber Hospital, Madrid, Spain

\section{María J Barco}

Gynecologic Centre ‘Bolonia’, Zaragoza, Spain

\section{Asim Kurjak (Corresponding Author)}

Professor, Department of Obstetrics and Gynecology, Dean of Faculty of Health Science, Dubrovnik International University, Dubrovnik Croatia, e-mail: asim.kurjak@public.carnet.hr 